\title{
Erythromycin Regulates Cigarette Smoke-Induced Proinflammatory Mediator Release Through Sirtuin 1-Nuclear Factor KB Axis in Macrophages and Mice Lungs
}

\author{
Nan Ma Ting-Ting Deng Qin Wang Zhou-Ling Luo Cai-Feng Zhu \\ Ju-Feng Qiu Xiao-Juan Tang Mei Huang Jing Bai Zhi-Yi He \\ Xiao-Ning Zhong Mei-Hua Li \\ Department of Respiratory Medicine, First Affiliated Hospital of Guangxi Medical University, Nanning, China
}

\section{Keywords \\ Erythromycin · Sirtuin $1 \cdot$ Nuclear factor-кB . \\ Proinflammatory cytokine $\cdot$ Chronic obstructive \\ pulmonary disease}

\begin{abstract}
Background: Macrolides have anti-inflammatory and antioxidative stress function, but their pharmacological regulation remains unclear. Sirtuin 1 (SIRT1) is redox-sensitive protein belongs to class III histone/protein deacetylases, SIRT1 regulates the acetylation/expression of nuclear factor $\mathrm{kB}$ (NF-KB) and is involved in the airway inflammation of chronic obstructive pulmonary disease. Objectives: The present study was designed to examine the effects of erythromycin (EM) on the SIRT1-NF-KB axis and NF-KB-dependent proinflammatory cytokines. Methods: Human macrophages were preincubated with EM and then treated with cigarette smoke extract (CSE). The mice were treated by injecting drugs to gastric with EM before cigarette smoke exposure. Reactive oxygen species (ROS) released by treated human macro-
\end{abstract}

\section{KARGER}

(c) 2019 S. Karger AG, Basel

E-Mail karger@karger.com

www.karger.com/pat phages were detected using flow cytometry. The expression of SIRT1 and NF-KB was analyzed by western blotting. SIRT1 and the RelA/p65 subunits of NF-KB interaction were detected by coimmunoprecipitation. We found that EM suppressed CSE-induced ROS released in human macrophages, which coincided with increases in SIRT1 protein expression in the macrophages and lungs of mice, resulting in suppressed NF-KB acetylation and expression correlated with a reduction of inflammatory mediators. Conclusion: These findings suggest that EM increased SIRT1, leading to acetylation/expression of NF-KB, and thereby decreasing cigarette smokedriven NF-KB-dependent proinflammatory cytokine.

(c) 2019 S. Karger AG, Basel

\section{Introduction}

There is increasing research proving the effects of macrolide therapy for chronic obstructive pulmonary disease (COPD) [1,2]. Long-term treatment with macrolide antibiotics such as erythromycin (EM) reduces 
COPD exacerbation [2-4]. Macrolides have anti-inflammatory effects $[2,5,6]$. Treatment with macrolide antibiotics is also used for cystic fibrosis and diffuse panbronchiolitis [7-9]. Macrolides demonstrate several immunomodulatory activities in vivo, including downregulation of inflammation, decreased production of reactive oxygen species (ROS), and inhibition of nuclear transcription factor activation $[8,10]$. However, the molecular mechanism underlying the anti-inflammatory and antioxidative stress action of macrolides remains to be determined.

$\mathrm{COPD}$ is characterized by a progressive decline in lung function and chronic inflammatory responses [11]. Cigarette smoking is the major factor for the ongoing inflammation in the airways and lung parenchyma, and the severity of airflow limitation is correlated with the degree of pulmonary inflammation $[12,13]$. Previous studies have demonstrated that one of the major etiologic factors driving inflammatory responses is oxidative stress in long-term exposure to cigarette smoke $[14,15]$. Oxidative stress can activate the nuclear factor $\kappa \mathrm{B}(\mathrm{NF}-\kappa \mathrm{B})$ pathway at many levels and NF- $\kappa B$ expression and activation is increased in COPD and correlates with increased release of NF- $\mathrm{KB}$-dependent proinflammatory cytokines [16$18]$.

Sirtuins belong to class III histone/protein deacetylases (HDACs) and are members of the silent information regulator 2 family [19]. In humans, there are 7 members of this family of deacetylases (Sirtuin 1 [SIRT1]-7) [20]. There is increasing interest in investigating the role of SIRT1 in inflammation and stress responses [19-22]. SIRT1 is a NAD+-dependent HDAC essential for maintaining silent chromatin via the deacetylation of histones and regulating gene transcription and protein functions [21]. Increasing evidence indicates that SIRT1 is a link between oxidative stress, inflammation, and cell aging/ senescence, all processes that are characteristic of COPD phenotypes, especially COPD/emphysema $[13,22]$. Previous studies indicate that SIRT1 can directly bind to NF$\kappa \mathrm{B}$ and deactivates NF- $\kappa \mathrm{B}$ RelA/p65 through deacetylation and proteasome degradation $[23,24]$. In the lung tissues of chronic smokers and COPD patients, SIRT1 expression is reduced by cigarette smoke [25]. Decreased SIRT1 expression is associated with increased NF- $\mathrm{kB}$ activation and the release of NF- $\mathrm{kB}$-dependent proinflammatory cytokines, consequently promoting the inflammatory reaction [25-27].

Macrophages are derived from monocytes and are considered to be important cells in perpetuating the inflammatory response of CS and play a key role in orches- trating chronic inflammation in patients with COPD [25]. Our previous studies showed that EM upregulated the expression of HDAC, resulting in decreased cigarette smoke-driven NF- $\kappa \mathrm{B}$ activation and NF- $\kappa \mathrm{B}$-dependent proinflammatory cytokines in human macrophages [9]. However, the precise molecular mechanisms of EM antiinflammatory and anti-oxidative stress remain unclear. This study was designed to identify the effects of EM on the SIRT1-NF- $\kappa B$ axis in human macrophages and the lungs of mice. The role of EM in the regulation of NF- $\kappa \mathrm{B}-$ dependent proinflammatory cytokines (TNF- $\alpha$ and IL-6 release) in human macrophage cells was also investigated. Our results provide a basis for the future development of EM as an effective treatment for COPD.

\section{Materials and Methods}

Cigarette Smoke Exposure in Mice

Specific pathogen-free inbred male BALB/c mice ( 8 weeks of age, 20-25 g body weight) were purchased from the Guangxi Medical University Laboratory Animal Center (Nanning, China). This study conformed to the Guide for the Care and Use of Laboratory Animals published by the US National Institutes of Health (8th Edition, National Research Council, 2011). All methods and experimental protocols in the present program were also approved by the laboratory animals ethics committee of Guangxi Medical University (the approval number: No. 20140403). All mice were housed in sterilized cages and maintained on a 12:12 h light:dark cycle and received sterilized food and water ad libitum.

Mice were randomly divided into 3 groups, 6 in each group. Briefly, in CS-exposed group, the mice were exposed whole body to 5 cigarettes (Nanning Zhenlong unfiltered cigarettes: $10 \mathrm{mg}$ of tar and $0.9 \mathrm{mg}$ of nicotine) 4 times a day with 30 -min smoke-free intervals in a closed $0.75 \mathrm{~m}^{3}$ room 5 days a week for 24 weeks. The control groups (air-exposed mice) were exposed to 24 weeks of air. In the EM treatment group, mice were treated by injecting drugs to gastric with EM ( $100 \mathrm{mg} \mathrm{kg}^{-1} /$ day) $1 \mathrm{~h}$ before the cigarette smoke exposure [28].

\section{Process of Bronchoalveolar Lavage Fluid}

The mice were sacrificed with sodium pentobarbital anesthesia $24 \mathrm{~h}$ after the last air or smoke exposure. Their lungs were lavaged via a cannula inserted into the trachea, and the left lobe was tied off and then instilled with $1 \mathrm{~mL}$ aliquots of saline. The first and second aliquots were combined and centrifuged, and the cell-free supernatants were frozen for later analyses. One part of the right lungs (30-50 mg) was homogenized for western blotting after lavaging.

Tissue Processing for Morphological

The left lungs were inflated by instilling $10 \%$ formalin at a constant pressure of $25 \mathrm{~cm} \mathrm{H} 2 \mathrm{O}$ (for $10 \mathrm{~min}$ ) and then ligated and removed. Inflated lungs were fixed for $24 \mathrm{~h}$ before embedding in paraffin. After paraffin embedding, 5 - $\mu \mathrm{m}$ sections were cut and stained with hematoxylin and eosin for histological analysis. For each animal, 10 fields at a magnification of $200 \times$ were captured 
randomly from the 4 different zones of the left lung. We determined the enlargement of alveolar spaces by mean linear intercept $(\mathrm{Lm})$ in the lungs of mice as described previously. Two investigators independently measured Lm in a blinded manner.

\section{Cell Lines and Cell Culture}

The human monocytic cell line U937 [29, 30] obtained from ATCC (CRL-1593.2; Shanghai, China) was grown in RPMI 1640 medium (Life Technologies, Gaithersburg, MD, USA) supplemented with 10\% fetal bovine serum (FBS; Excell Bio, Shanghai, China), $2 \mathrm{mM}$ L-glutamine, $100 \mu \mathrm{g} / \mathrm{mL}$ penicillin, $100 \mathrm{U} / \mathrm{mL}$ streptomycin, $1 \%$ nonessential amino acids, $1 \%$ sodium pyruvate, $1 \mu \mathrm{g} /$ $\mathrm{mL}$ human holotransferrin, and $1 \mathrm{mM}$ oxaloacetic acid. The cells were cultured at $37^{\circ} \mathrm{C}$ in a humidified atmosphere containing $5 \%$ $\mathrm{CO}_{2}$. The U937 cells were differentiated into macrophages using phorbol 12-myristate 13-acetate $(10 \mathrm{ng} / \mathrm{mL}$; Sigma-Aldrich, St. Louis, MO, USA), according to standard procedures [31]. Cell differentiation and adherence were assessed using light microscopy. In most cases, over $85 \%$ of the total cell population adhered to the surface with a distinctive altered morphology (macrophage like).

\section{3-(4,5-Dimethylthiazol-2-yl)-2,5-Diphenyl Tetrazolium}

Bromide Assay

The effects of cigarette smoke extract (CSE) and EM on cell viability were evaluated using the 3-(4,5-dimethylthiazol-2-yl)-2,5diphenyl tetrazolium bromide assay as previously described [9]. The human macrophage cells were cultured in 96-well plastic plates at a density of 5,000 cells/well at $37^{\circ} \mathrm{C}, 5 \% \mathrm{CO}_{2}$, and $96 \%$ air saturation for $24-72 \mathrm{~h}$ in the presence or absence of CSE $(0.1,1$, and $5 \%)$ or $\operatorname{EM}(0.1,1$, and $20 \mu \mathrm{g} / \mathrm{mL})$. The 3-(4,5-dimethylthiazol2-yl)-2,5-diphenyl tetrazolium bromide solution $(20 \mu \mathrm{L} /$ well and $5 \mathrm{mg} / \mathrm{mL}$ ) was added, and the cells were cultured for $4 \mathrm{~h}$. After media removal, 100\% DMSO $(200 \mu \mathrm{L})$ was added to dissolve the formed crystals. The optical densities at $570 \mathrm{~nm}$ were measured with a spectrophotometric microtiter plate reader (BioTek, ELX800, Highland Park, Winooski, VT, USA). The morphology of the cultured human macrophage cells was evaluated under a microscope (Nikon, TS100-F, Tokyo, Japan) throughout the course of the experiments.

\section{Preparation of Aqueous CSE}

Research-grade cigarettes were smoked to $0.5 \mathrm{~cm}$ above the filter in a fume hood using the methods developed by Carp [32] and Se-Ran [33] with a slight modification as previously described [34]. CSE (10\%) was prepared by bubbling smoke from 2 cigarettes into $20 \mathrm{~mL}$ of serum-free RPMI at a rate of 1 cigarette/min. The $\mathrm{pH}$ of the RPMI was adjusted to 7.4, optical densities at $350 \mathrm{~nm}$ were determined $(0.81 \pm 0.03)$, and the media were sterile filtered with a $0.45-\mu \mathrm{m}$ membrane filter (25-mm Acrodisc; Pall, Ann Arbor, MI, USA). The CSE was freshly prepared on the day of the experiment. The patterns of absorbance at $320 \mathrm{~nm}$ (spectrogram) showed few differences between each CSE preparation. We prepared control media by bubbling air through $20 \mathrm{~mL}$ of the serum-free RPMI, adjusting the $\mathrm{pH}$ to 7.4 , and sterile filtering as described above.

\section{CSE and EM Treatments}

Differentiated U937 cells were seeded at a density of $1-2 \times 10^{6}$ cells/well in 6-well culture plates in a total final medium volume of $2 \mathrm{~mL}$ and grown in RPMI containing $10 \%$ FBS to $~ 80$ to $90 \%$ confluence. The cells were washed in phosphate-buffered saline (PBS) and then exposed to various treatments in media containing $1 \%$ FBS. All treatments were performed in duplicate. The cells were divided into several groups: CSE (treated with 1\% CSE), EM (pretreated with $1 \mu \mathrm{g} / \mathrm{mL}$ of EM for $24 \mathrm{~h}$ before treated with $1 \%$ CSE), pyrrolidine dithiocarbamate (PDTC; treated with NF- $\kappa$ B inhibitor PDTC, $10 \mathrm{nM}$ of PDTC for $24 \mathrm{~h}$ ) [35], and NAM (nicotinamide, a SIRT1 inhibitor, $20 \mathrm{mM}$, for $24 \mathrm{~h}$ ) [36]. The cells were cultured at $37^{\circ} \mathrm{C}$ with $5 \% \mathrm{CO}_{2}$. After culture with the drugs, the cells were washed with cold PBS and then lysed to measure the SIRT1 levels. Culture media from these macrophages were collected for TNF- $\alpha$, IL- 6 , and TNF- $\alpha$ assays and stored at $-80^{\circ} \mathrm{C}$ until use.

\section{Measurement of ROS by Flow Cytometry}

ROS were measured by flow cytometry using 5-(-6)-carboxy-2,7-dichlorodihydrofluorescein diacetate (H2DCFDA) dye. The cells were seeded at a density of $2.5 \times 10^{5}$ cells/well in 6-well culture plates in a final volume of $2 \mathrm{~mL}$ of RPMI with $1 \%$ FBS and were grown to $\sim 80$ to $90 \%$ confluency. Freshly prepared CSE was added, and the cells were incubated for $24 \mathrm{~h}$, washed 3 times with prewarmed PBS, resuspended in $1 \mathrm{~mL}$ of PBS, and incubated with or without H2DCFDA $(10 \mu \mathrm{M})$ for $0.5 \mathrm{~h}$. The cells were washed and resuspended in PBS, and flow cytometric analysis was performed with an Elite flow cytometer (FACSCanto II, BD Bioscience, San Jose, CA, USA). Dead cells detected with propidium iodide $(10 \mu \mathrm{g} /$ $\mathrm{mL}$ ) by forward and side scattering were gated out. A minimum of 10,000 events was acquired for each sample. The debris was gated out, and analyses were performed only on the live monocytic populations $[37,38]$.

\section{Western Blotting Analysis for SIRT1 and NF- $\kappa B$}

Cellular proteins were extracted from the treated U937 cells with 10\% Nonidet P-40 lysis buffer (RIPA buffer, \#89900; Thermo Fisher Scientific Inc., Rockford, IL, USA) supplemented with 2 protease inhibitor cocktails (PMSF, ST506; Biyuntian, Shanghai, China; phosphatase inhibitor cocktail, Cat. No.040906845001; Roche, Mannheim, Germany) [39, 40]. The mice lungs were homogenized and treated with $10 \%$ Nonidet P-40 lysis buffer (RIPA buffer, \#89900; Thermo Fisher Scientific Inc., Rockford, IL, USA) supplemented with protease inhibitor cocktail (PMSF, ST506; Biyuntian, Shanghai, China). After $30 \mathrm{~min}$ of incubation under $4{ }^{\circ} \mathrm{C}$, the cell lysates were centrifuged, and supernatants containing the proteins were collected. Protein quantitation was performed using the NanoDrop 2000 spectrophotometer (Thermo Fisher Scientific, Middlesex, MA, USA) following the manufacturer's instructions. Isolated soluble proteins $(20 \mu \mathrm{g})$ were electrophoresed on 10\% PAGE gels and electroblotted onto $0.45-\mu \mathrm{m}$ PVDF membranes. The membranes were blocked with 5\% nonfat dry milk for $1 \mathrm{~h}$, incubated with Tris-buffered saline (TBS) with $0.1 \%$ Tween 20 for $1 \mathrm{~h}$, and then incubated with rabbit polyclonal anti-human-SIRT1 (1:300 diluted in TBS) or anti-NF- $\mathrm{BB}$ (1:1,000 diluted in TBS) antibody for $24 \mathrm{~h}$ (SIRT1 rabbit $\mathrm{mAb}$, D1D7, NF- $\kappa$ B rabbit mAb, D14E12; Cell Signaling Technology, Danvers, MA, USA) [41]. After washing with TBS, the SIRT1 and $\mathrm{NF}-\kappa \mathrm{B}$ protein expressions were detected with goat anti-rabbit antibody (goat anti-rabbit IgG-HRP: sc-200; Santa Cruz Biotechnology, Dallas, TX, USA), conjugated to horseradish peroxidase (1:10,000 diluted in TBS) for $1 \mathrm{~h}$, and visualized with enhanced chemiluminescence (SuperSignal West Pico Chemiluminescent Substrate, Product \#34077; Thermo Fisher, Middlesex, MA, USA). 


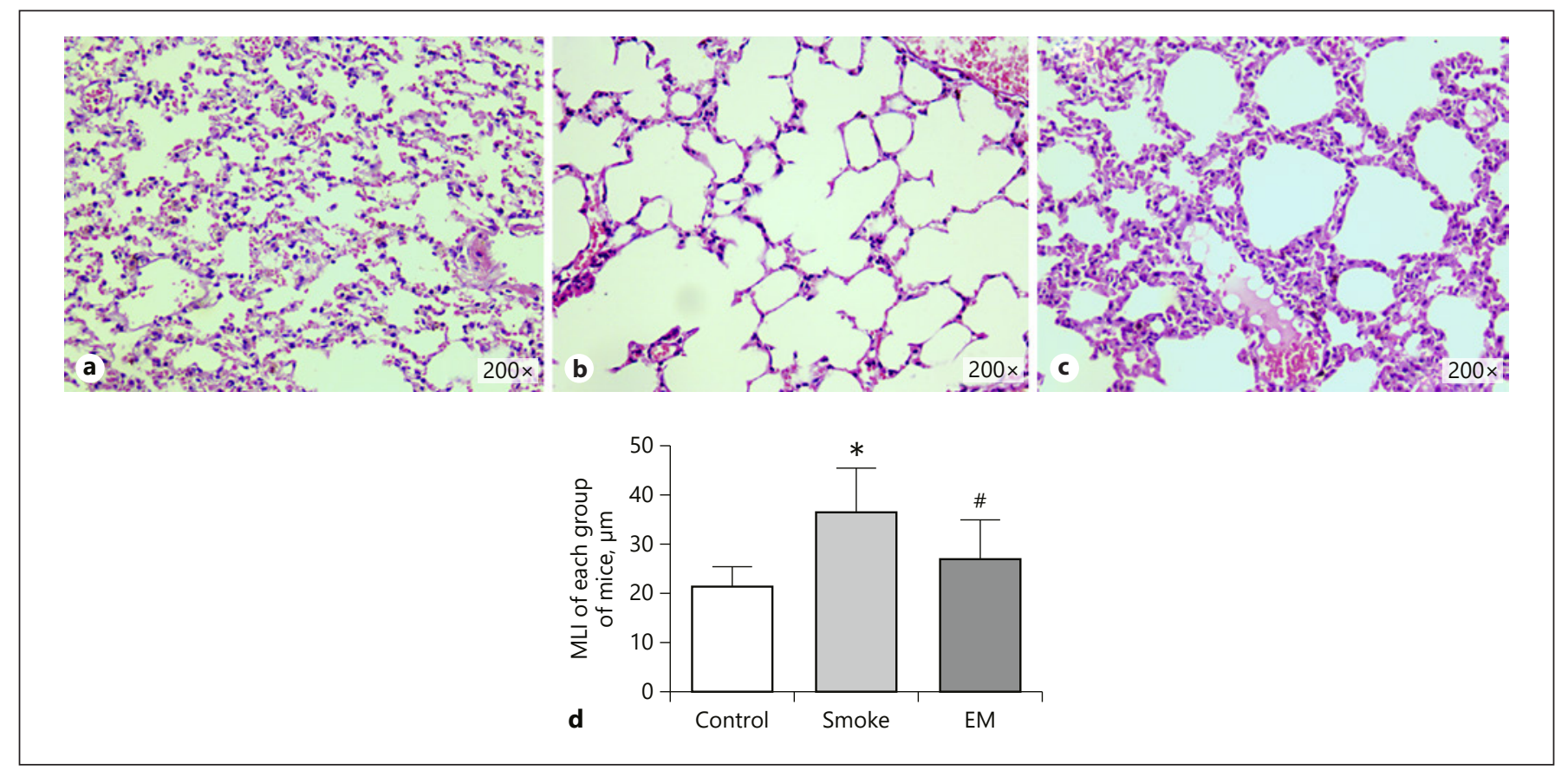

Fig. 1. Photomicrographs of hematoxylin and eosin-stained lung tissue of air-exposed (a), smoke-exposed (b), and EM-treated (c) mice at 24 weeks $(200 \times)$. Smoke exposure significantly induced alveolar wall destruction and airspace enlargement in the mice. Treated with EM relieved this effect. d Destruction of the alveolar

\section{Coimmunoprecipitation of Protein Complexes}

For coimmunoprecipitation of endogenous protein complexes from whole-cell extracts, the cells were lysed with $10 \%$ Nonidet P-40 lysis buffer supplemented with a protease inhibitor cocktail (leupeptin, aprotinin, pepstatin, and PMSF, phosphatase inhibitor cocktail; Roche, Mannheim, Germany) for 30 min on ice and centrifuged at $12,000 \mathrm{~g}$ for $5 \mathrm{~min}$ at $4{ }^{\circ} \mathrm{C}$ [23]. Cellular lysates were incubated with an anti-NF- $\kappa$ B antibody (1:100 dilution; Cell Signaling Technology, Danvers, MA, USA) and incubated at $4{ }^{\circ} \mathrm{C}$ overnight, followed by incubation with protein A-Sepharose overnight at $4{ }^{\circ} \mathrm{C}$. The immunoprecipitation complex was isolated by centrifugation at $10,000 \mathrm{~g}$ for $5 \mathrm{~min}$ at $4{ }^{\circ} \mathrm{C}$, and the immunoprecipitated proteins were detected by western blotting $[23,41]$. The levels of SIRT1 adducts with RelA/p65 NF- $\kappa B$ were analyzed by immunoblotting with anti-SIRT1 antibody (SIRT1 rabbit mAb, D1D7; Cell Signaling Technology, Danvers, MA, USA), and a specific acetylated lysine 310 residue (K310) antibody (Acetyl-NF- $\kappa B$ p65 [Lys310] Antibody, Cell Signaling Technology, Danvers, MA, USA) was analyzed for RelA/p65, respectively.

\section{ELISA for IL-6 and TNF- $\alpha$}

Culture media were collected after treatments and centrifuged at $1,000 \mathrm{~g}$ for $15 \mathrm{~min}$. The supernatants were collected and stored at $-20^{\circ} \mathrm{C}$ until analysis. IL- 6 and TNF- $\alpha$ levels in the supernatants of macrophages and bronchoalveolar lavage fluid of mice were determined by sandwich ELISA $[42,43]$ using the respective dual antibody kits (IL-6 ELISA Kit, TNF- $\alpha$ ELISA Kit; Wuhan Huamei Systems, Wuhan, China) according to the manufacturer's instructions [44]. walls was determined by measuring the MLI. Smoke exposure significantly increased the MLI of the mice compared to control group, while treated with EM decreased the MLI compared to the smoke group $\left(n=6,{ }^{*} p<0.05\right.$ compared to the control values; ${ }^{\#} p<$ 0.05 compared to the smoke). EM, erythromycin.

\section{Statistical Analysis}

The data are presented as means \pm SEM, and statistical analysis was performed with SPSS 16.0 for PC (SPSS Inc., Chicago, IL, USA) using a one-way ANOVA followed by the Friedman test and the Wilcoxon signed-rank test for multiple comparisons. Statistical significance was assigned at $p<0.05$.

\section{Results}

\section{Photomicrographs of Hematoxylin and Eosin-Stained Mice's Lung Tissue}

Photomicrographs of hematoxylin and eosin-stained lung tissue of air-exposed (Fig. 1a), smoke-exposed (Fig. 1b), and treated with EM (Fig. 1c) mice at 24 weeks (the cells were observed under an inverted microscope at a magnification of $\times 200$ ). Smoke exposure clearly induced alveolar wall destruction and airspace enlargement in mice. Alveolar enlargement was still seen in Figure 1c (EM group), but the extent of alveolar destruction was lower than in Figure 1b. Destruction of alveolar walls was determined by measuring the MLI (mean linear intercept). The MLI of the smoke group was significantly increased compared to the control group, and treated with 
EM decreased the MLI (Fig. 1d, $n=6, p<0.05$ ). Data are shown as mean \pm SEM. ${ }^{*} P<0.05$ compared to the control values; ${ }^{*} p<0.05$ compared to the smoke (Student $t$ test).

\section{Effects of EM on CSE-Induced SIRT1 and NF- $\kappa B$}

\section{Protein Expression}

The effects of EM on CSE-induced SIRT1 protein expression in the mice lungs and human macrophages were measured using Western blotting. Preincubated with EM $(1 \mu \mathrm{g} / \mathrm{mL})$ for $24 \mathrm{~h}$ increased SIRT1 protein expression in human macrophages, as a negative control, NAM decreased SIRT1 protein expression (Fig. 2a, b; $n=5$ ). Smoke decreased SIRT1 expression, while EM increased SIRT1 expression in the mice lungs (Fig. 2e, f; $n=5$ ).

In human macrophages, treated with $1 \%$ CSE for $24 \mathrm{~h}$ increased NF- $\kappa B$ protein expression. However, pretreatment with EM $(1 \mu \mathrm{g} / \mathrm{mL})$ for 24 and $48 \mathrm{~h}$ attenuated CSEinduced NF- $\kappa \mathrm{B}$ protein expression. As a negative control, PDTC inhibited NF- $\kappa B$ activation (Fig. $2 c, d ; n=5$ ). Our data also indicated that smoke increased NF- $\kappa \mathrm{B}$ expression and EM attenuated this effect in lung of mice (Fig. 2g, $\mathrm{h} ; n=6)$.

Further experiments were performed to determine whether EM regulates the acetylation of NF- $\kappa B$ via SIRT1 by coimmunoprecipitation. CSE treatment decreased SIRT1, resulting in increased acetylation of RelA/p65 NF$\kappa B$. EM significantly increased SIRT1 leading to decreased acetylation of RelA/p65 NF- $\mathrm{BB}$ in human macrophages (Fig. 2i, j; $n=3$ ). Data are shown as mean \pm SEM. ${ }^{*} p<$ 0.05 compared to the control values; ${ }^{*} p<0.05$ compared to the smoke/CSE (Student $t$ test).

\section{Effect of EM, CSE on Cell Viability and ROS}

\section{Generation}

The human macrophage cells were exposed to $0.1,1$, and $20 \mu \mathrm{g} / \mathrm{mL}$ EM for 24, 48, and $72 \mathrm{~h}$. Human macrophage cell viability was decreased when the cells were treated with $20 \mu \mathrm{g} / \mathrm{mL}$ EM for $24 \mathrm{~h}$ and $1 \mu \mathrm{g} / \mathrm{mL}$ EM for $72 \mathrm{~h}$. EM at a concentration of $0.1 \mu \mathrm{g} / \mathrm{mL}$ for 24,48 , and $72 \mathrm{~h}$ or $1 \mu \mathrm{g} / \mathrm{mL}$ for 24 and $48 \mathrm{~h}$ did not affect cell viability; at a concentration of $20 \mu \mathrm{g} / \mathrm{mL}$, human macrophage cell viability decreased significantly. Human macrophage cell viability was decreased when the cells were treated with 5\% CSE for $24 \mathrm{~h}$. CSE at a concentration of $0.1 \%$ for 24,48 , and $72 \mathrm{~h}$ or $1 \%$ for 24,48 , and $72 \mathrm{~h}$ did not affect cell viability; at a concentration of $5 \%$, cell viability decreased significantly (Fig. 3a, $n=5$ ).

We determined whether EM attenuated CSE-induced ROS generation by flow cytometry (Fig. 3b). Cells were seeded in 6-well plates $\left(2.5 \times 10^{5}\right.$ cells/well $)$, preincubated with EM $(1 \mu \mathrm{g} / \mathrm{mL})$ for 24 or $48 \mathrm{~h}$, and then treated with CSE (1\%) for $24 \mathrm{~h}$. The cells were washed with PBS and incubated with H2DCFDA for $30 \mathrm{~min}$. The cell lysates were resuspended in PBS, and the ROS concentrations were measured using flow cytometry (B) $[37,45,46]$. Our data showed that CSE increased ROS production significantly, which was attenuated by EM (Fig. $3 c, n=3$, ${ }^{*} p<0.05$ compared to the control values; ${ }^{*} p<0.05$ compared to $1 \%$ CSE), suggesting that EM inhibits CSE-induced ROS generation in vitro.

\section{Effects of EM on the Release of CSE-Induced}

Inflammatory Mediators in Cultured Human

Macrophages and Lung of Mice

We next determined the effects of EM on the release of CSE-induced inflammatory mediators in cultured human macrophages and lung of mice. We measured IL-6 and TNF- $\alpha$ the culture media using ELISA. Treated with $1 \%$ CSE for $24 \mathrm{~h}$ increased the release of these inflammatory mediators. However, preincubation with EM $(1 \mu \mathrm{g} /$ $\mathrm{mL}$ ) for $24 \mathrm{~h}$ inhibited CSE-mediated proinflammatory cytokine release. In the mice BAL, smoke increased TNF- $\alpha$ release and treated with EM significantly decreased smoke-driven TNF- $\alpha$ release (Fig. 4c).

\section{Discussion}

Macrolides exert immunodulatory and anti-inflammatory effects that may benefit patients with COPD [47]. Long-term use of macrolides or antibiotics can suppress bronchial colonization and consequent exacerbations [48]. In the clinic, EM treatment $(250 \mathrm{mg}$ twice daily for 1 year) leads to a significant reduction (35\%) in the frequency of exacerbations compared to placebo [48]. Macrolides have various anti-inflammatory effects, including reducing the production of cytokines such as TNF- $\alpha$ and IL-6 $[8,17,49]$, which are time- and dose dependent [8]. Our previous study shows that the mechanism of the anti-inflammatory effect of EM was related to the regulation of HDAC protein in macrophages, but the particular mechanism needs further study [9]. The present study focused on the role of SIRT1, which is a NAD+-dependent HDAC, that regulates proinflammatory cytokines, apoptosis, stress resistance, metabolism, senescence, differentiation, and aging, all of which are linked to COPD [50, 51]. NF$\kappa \mathrm{B}$ protein is the master regulator of inflammation, and SIRT1 also controls inflammation through regulating NF$\kappa \mathrm{B}$ signaling by deacetylating the p65 subunit of the complex, thereby inhibiting NF-kB signaling [19]. 
Fig. 2. a Representative western blotting and analyses of SIRT1 protein levels in human macrophages. b Relative densities (\% of control) of SIRT1 in human macrophages after treated with CSE or NAM for $24 \mathrm{~h}$ alone or in combination with EM preincubated. Treatment with $1 \%$ CSE for 24 $\mathrm{h}$ reduced SIRT1 protein expression. Preincubated with EM $(1 \mu \mathrm{g} / \mathrm{mL})$ for $24 \mathrm{~h}$ increased SIRT1 protein expression. As a negative control, NAM decreased SIRT1 protein expression $(n=5)$. c Representative western blotting and analyses of NF- $\kappa B$ in the mice lungs levels in human macrophages. d Relative densities (\% of control) of NF- $\kappa \mathrm{B}$ in human macrophages after treated with CSE for $24 \mathrm{~h}$ alone or in combination with EM preincubated. Treated with $1 \%$ CSE for $24 \mathrm{~h}$ increased NF- $\kappa \mathrm{B}$ protein expression. Preincubated with EM (1 $\mu \mathrm{g} / \mathrm{mL}$ ) for $24 \mathrm{~h}$ attenuated CSE-induced NF- $\kappa \mathrm{B}$ protein expression. As a negative control, PDTC decreased NF- $\kappa \mathrm{B}$ protein expression. Treated with 1\% CSE and NAM $24 \mathrm{~h}$ in combination increased NF$\kappa \mathrm{B}$ protein expression $(n=3)$. e Representative western blotting and analyses of SIRT1 protein levels in the mice lungs. $\mathbf{f}$ Relative densities (\% of control) of SIRT1 in the mice lungs; smoke decreased SIRT1 expression and EM attenuated this effect ( $n$ $=5$ ). $\mathbf{g}$ Representative western blotting of NF- $\kappa \mathrm{B}$ protein levels in the mice lungs. $\mathbf{h}$ $\mathrm{NF}-\kappa \mathrm{B}$ protein levels and relative densities (\% of control) of NF- $\kappa \mathrm{B}$ in the mice lungs; smoke increased NF- $\mathrm{B}$ expression and EM attenuated this effect $(n=6)$. i Representative of NF- $\kappa \mathrm{B} / \mathrm{SIRT} 1$ protein bands. CSE (1\%) significantly increased Ac-RelA/ p65 NF- $\kappa$ B levels in the SIRT1-Ac-RelA/ p65 complex. EM pre-incubated $(1 \mu \mathrm{g} / \mathrm{mL})$ for $24 \mathrm{~h}$ attenuated CSE-induced Ac-RelA/ p65 expression. Equal amounts (30 ug) of immunoprecipitated SIRT1 protein was used for western blotting. $\mathbf{j}$ Relative intensity (\% of Ac-RelA/p65 NF- $\kappa$ B) of SIRT1 protein bands. The data are presented as means \pm SEM. ${ }^{*} p<0.05$ versus control; ${ }^{*} p$ $<0.05$ versus Smoke/CSE (Student $t$ test). SIRT1, Sirtuin 1; CSE, cigarette smoke extract; EM, erythromycin; PDTC, pyrrolidine dithiocarbamate; NF- $\kappa \mathrm{B}$, nuclear factor $\kappa \mathrm{B}$; Co-IP, co-immunoprecipitation.
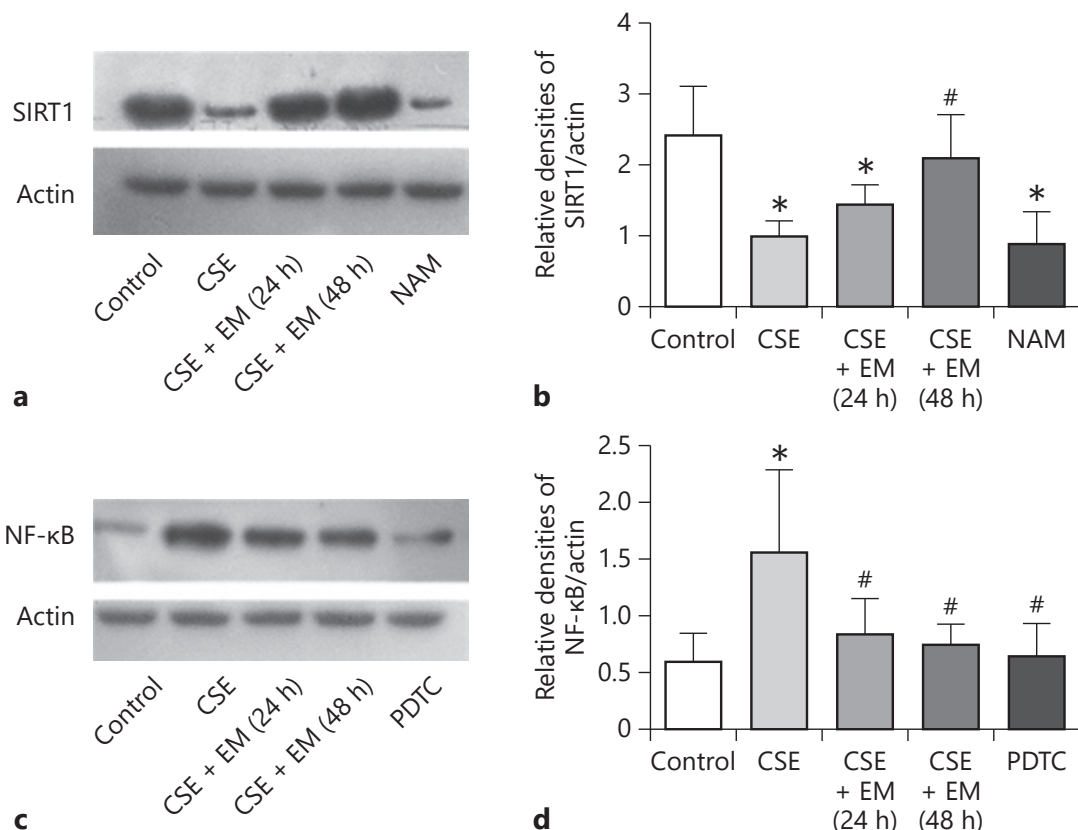

(24 h) (48 h)
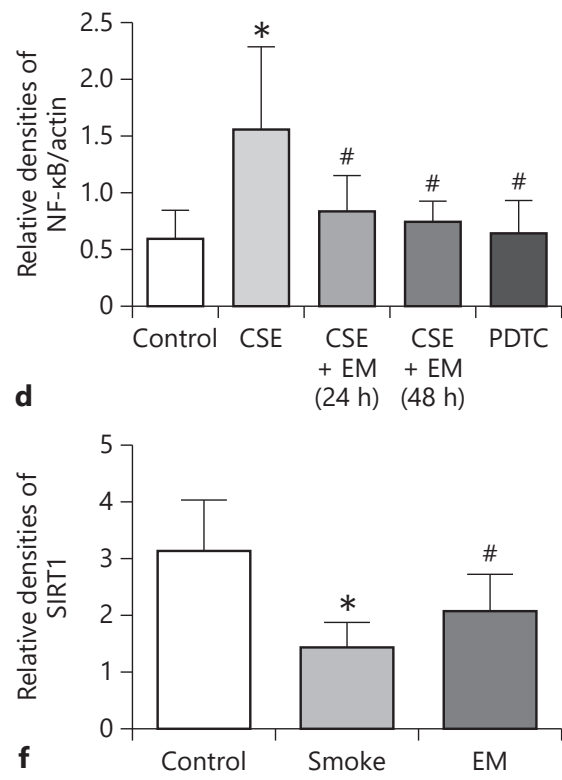

e
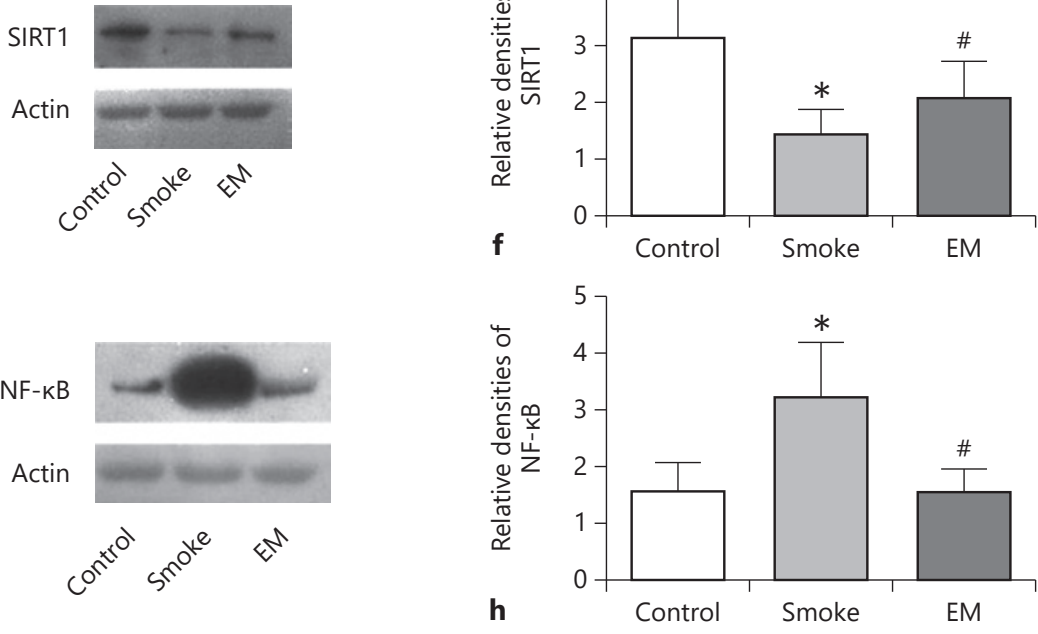

g

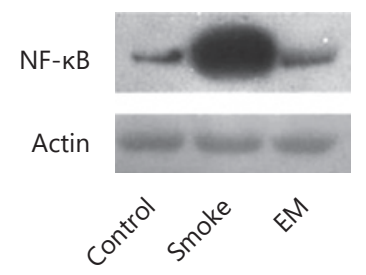

$\mathbf{h}$

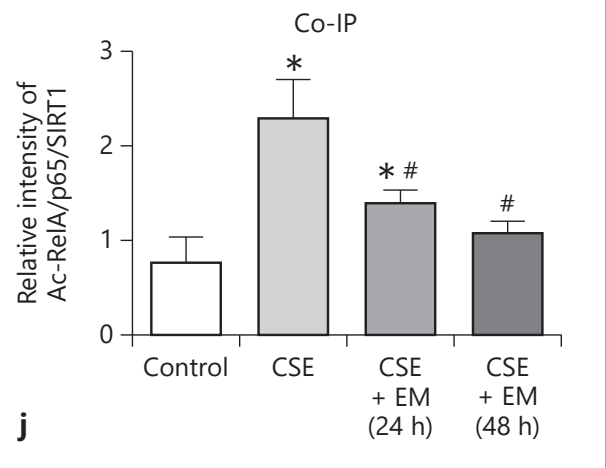




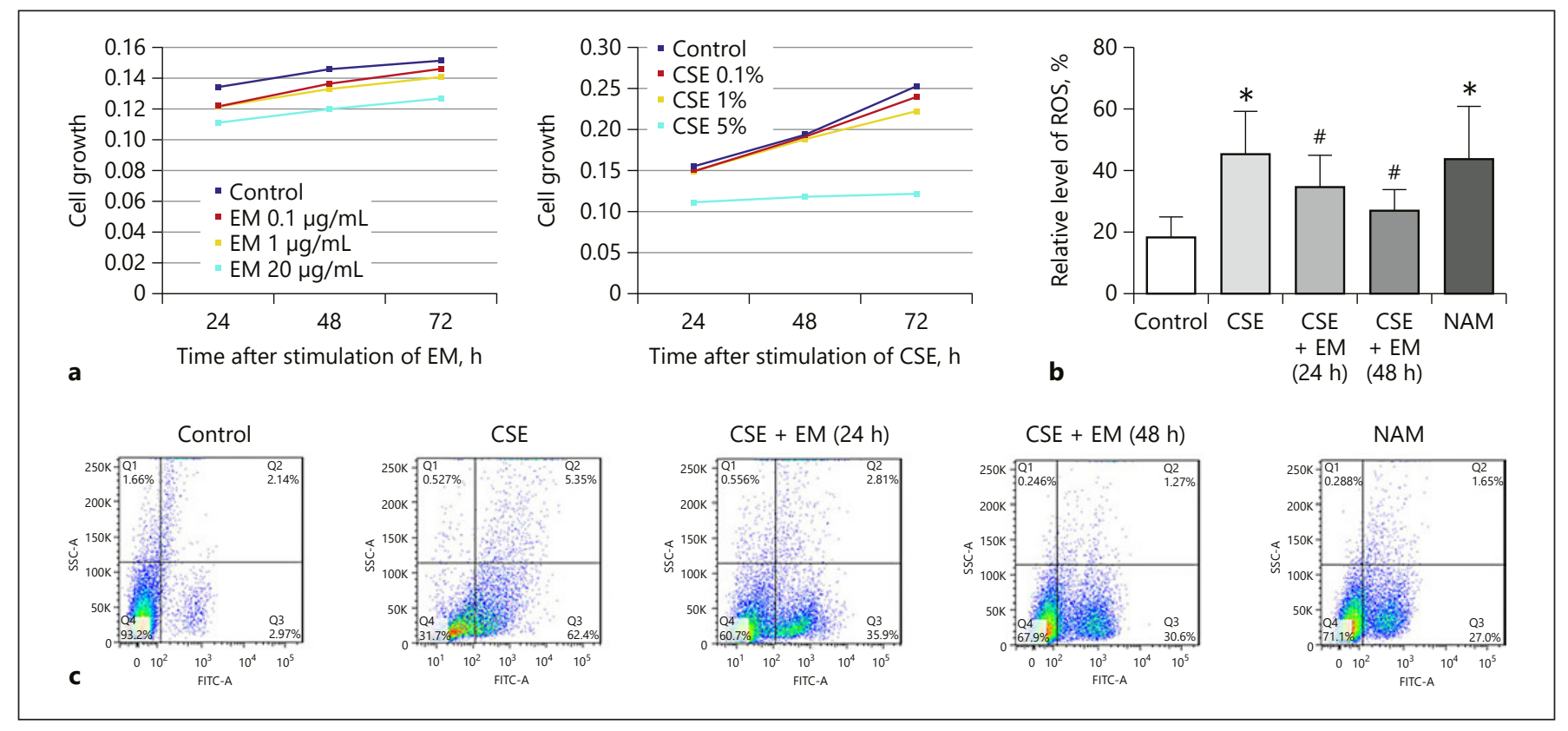

Fig. 3. a Effects of CSE and EM on the growth of human macrophage cells. Proliferation levels of human macrophage cells were determined in relation to the growth curve based on the measurement of the OD at each time point $(n=5)$. c Treated with CSE significantly increased ROS generation; EM inhibited the CSE-induced ROS generation, especially at $48 \mathrm{~h}$. NAM significantly in- creased ROS generation. b Flow cytometry of ROS generation, by measuring FITC-A (fluorescein isothiocyanate-area) and SSC-A (side scatter-area). ${ }^{*} p<0.05$ vs. CSE; ${ }^{\#} p<0.01$ vs. control. CSE, cigarette smoke extract; EM, erythromycin; ROS, reactive oxygen species.

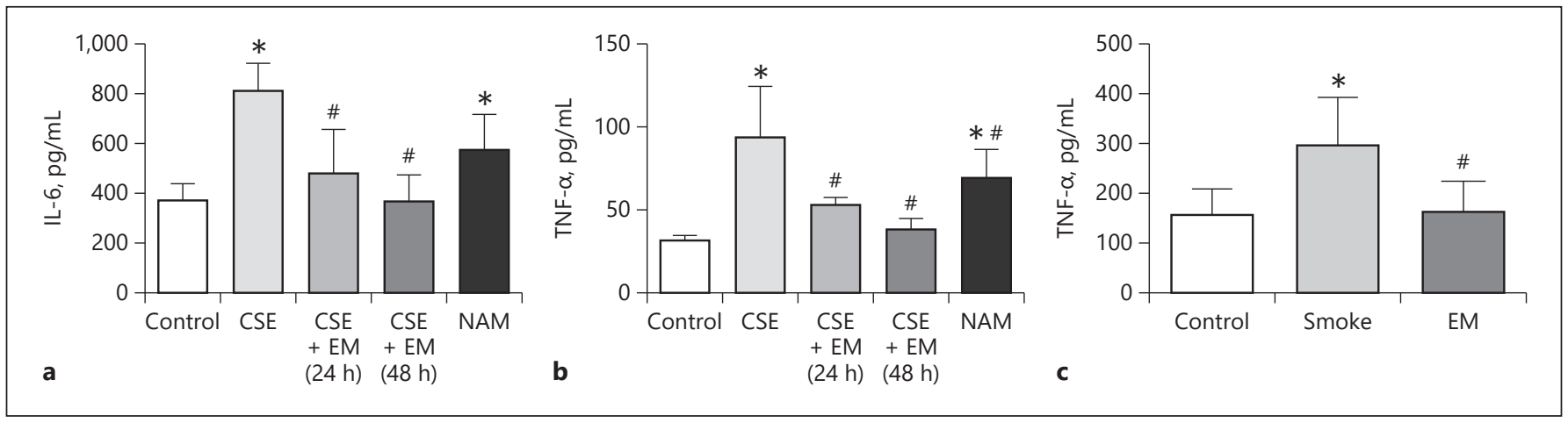

Fig. 4. a, b Treated with $1 \%$ CSE for $24 \mathrm{~h}$ increased the release of these inflammatory mediators. Preincubation with EM $(1 \mu \mathrm{g} / \mathrm{mL})$ for $24 \mathrm{~h}$ inhibited CSE-mediated proinflammatory cytokine release $(n=5)$. The data are presented as means \pm SEM, ${ }^{*} p<0.05$ vs. control; ${ }^{\#} p<0.05$ vs. CSE. c Smoke increased TNF- $a$ release

It is well known that CS-induced oxidative stress is responsible for proinflammatory cytokine release in the lungs $[16,25]$. The results of the present study showed that cigarette smoke induced ROS levels in cultured human macrophages. EM pretreatment reduced CSE-induced ROS generation, indicating that ROS reduction is and treated with EM significantly decreased smoke-driven TNF- $a$ release. The data are presented as means $\pm \mathrm{SEM},{ }^{*} p<0.05$ vs. control; ${ }^{\#} p<0.05$ vs. smoke. IL-6, interleukin-6; CSE, cigarette smoke extract; EM, erythromycin.

the major mechanism of EM's protective role in cell damage [9]. Cigarette smoke causes oxidative stress by generating ROS, thus causing cell injury and lung tissue damage $[16,52]$. The results of the present study showed that cigarette smoke induced ROS levels in cultured human macrophages. EM preincubated reduced CSE-in- 
duced ROS generation, indicating that ROS reduction is the major mechanism of EM's protective role in cell damage. CSE damage to mitochondrial proteins by carbonyl stress, which drives further endogenous ROS production by the damaged mitochondria $[16,52]$. Previous research demonstrated that EM inhibited mitochondria induced by human lactoferrin in yeast, resulting in a reduction of ROS released by mitochondria [53]. Our study was consistent with previous research [9]. EM restrained CSE-mediated induction of ROS release in human macrophages. However, the mechanism of EM on macrophage mitochondria still needs further research. Our study showed that as a SIRT1 inhibitor, NAM increased the release of ROS in human macrophages. Eric reported that the decrease in SIRT1 protein levels is correlated with the downregulation of deacetylation and activation of PGC-1 $\alpha$. Transactivation of estrogen-related receptor alpha by PGC-1 $\alpha$ decreases transcription of SIRT3, resulting in an increase in ROS [54]. Thus, it is tempting to speculate that NAM increased ROS release in human macrophages via the SIRT1-SIRT3 axis; the molecular mechanism needs further study. CSE-induced oxidative stress causes tissue damage resulting in the formation of carbonyl stress [15] and damage to mitochondrial proteins by carbonyl stress, which both drive further endogenous ROS production by the damaged mitochondria $[16,52]$. We therefore speculated that protecting the mitochondria from carbonyl stress might be the molecular mechanism underlying the EM-induced reduction in ROS levels.

We further studied the effect of pharmacological regulation of EM on SIRT1 expressed and the role of SIRT1 in proinflammatory cytokine release in response to CS exposure in BAL of mice lungs and human macrophages. Many inflammatory cytokines are significantly increased in the BAL of smokers [55]. Alveolar macrophages are considered to be important cells in the inflammatory response of CS [17]. Our data demonstrated that CSE treatment significantly upregulated the release of proinflammatory mediators such as TNF- $\alpha$ concomitant with decreased levels of SIRT1 protein in mice lungs and human macrophages. Yang and Saravanan reported that CS-mediated decreased SIRT1 levels were associated with increased inflammatory cytokines in the lung homogenate of smokers and MonoMac6 cells $[25,26]$. The mechanism by which CSE reduces SIRT1 is not fully understood; however, it is possible that CSE-derived oxidants lower the Michaelis-Menten constant $(\mathrm{Km})$ of SIRT1, alter the NAD+/NADH ratio, and induce oxidative modification of SIRT1 [26]. Our data are in agree- ment with previous studies. NAM is known to downregulate the expression of SIRT1 [56]. Our experimental results show that the increased release of proinflammatory mediator is associated with NAM inhibition of SIRT1 expression. Decreased expression of SIRT1 promoted NF- $\kappa B$ acetylation and transcription of IL- 6 and TNF- $\alpha[27,57,58]$. Our findings support these observations and verify the importance of SIRT1 in the regulation of proinflammatory mediators such as IL-6 and TNF- $\alpha$ in vivo and vitro. Furthermore, our current results demonstrate that EM increased SIRT1 levels are correlated with a reduction of proinflammatory cytokines in mice lungs and human macrophages. Previously, we had shown that EM inhibits oxidative stress which is induced by CSE. It has been reported that SIRT1 is a redox-sensitive deacetylase, which is post-translationally modified by oxidants and carbonyl stress, and that CSE can reduce SIRT1 protein levels through regulating oxidants and carbonyl stress [41]. In contrast, resveratrol is known to simulate SIRT1 activity and expression $[18,59]$ and significantly inhibits CSE-induced cytokine release and increases SIRT1 activity and expression in MonoMac6 cells [26]. In light of our data, it can thus be construed that EM increase SIRT1, resulting in decreased inflammatory CSE-driven cytokines. However, further studies are required to determine whether EM increased SIRT1 is directly associated with the decline of ROS in macrophages.

It has been well documented that SIRT1 is involved in the regulation of NF- $\mathrm{KB}[24,25,60]$, participating in the regulation of inflammatory responses $[25,61]$. Our data show that SIRT1 reduction induced by CSE leads to an increase in the acetylation of RelA/p65 NF- $\kappa \mathrm{B}$ and the induction of proinflammatory mediators. Previous studies demonstrated that SIRT1 physically interacts with the RelA/p65 subunit of NF- $\kappa \mathrm{B}$ and inhibits transcription by deacetylating RelA/p65 at lysine $310[25,62$, 63]. Therefore, increased posttranslational modifications of SIRT1 lead to a disruption of the RelA/p65SIRT1 complex, which culminates in acetylation and persistent activation of NF- $\kappa \mathrm{B}$ in response to CSE in macrophages [25]. EM increased SIRT1 activation, leading to deacetylation of NF- $\kappa B$ and reduction of proinflammatory cytokines in human macrophages. Activated SIRT1 first directly binds and deactivates NF- $\mathrm{BB}$ RelA/p65 through deacetylation and proteasome degradation [20]. Resveratrol is known to stimulate SIRT1 activity and expression [64] and could inhibit the NF- $\kappa B$ inflammation pathway through activating SIRT1 in MC3T3-E1 cells [65]. Yang et al. [26] demonstrated that 
resveratrol activated SIRT1 leading to reduced cigarette smoke-driven NF- $\kappa \mathrm{B}$-dependent proinflammatory cytokine release in macrophages in vitro. Thus, our study shows for the first time that EM upgrade SIRT1 would have an inhibition on the acetylation of NF- $\kappa$ B RelA/ p65.

In conclusion, the present study demonstrated that CSE decreased SIRT1 expression, thereby disrupting the SIRT1-RelA/p65 complex and increasing activation of RelA/p 65 NF- $\mathrm{kB}$, resulting in increased levels of proinflammatory cytokines. As an inhibitor of SIRT1, NAM increased the levels of proinflammatory mediators, suggesting that SIRT1 is related to the release of proinflammatory cytokines induced by CSEs. Our study shows for the first time that EM increased SIRT1 expression which was decreased by cigarette smoke, leading to the acetylation of RelA/p65 and thereby decreased cigarette smoke-driven NF- $\kappa \mathrm{B}$-dependent proinflammatory cytokines released in macrophages in vitro and in mice lungs in vivo. Considering its convenience and low cost, EM has the potential to be used for the treatment of COPD.

\section{Acknowledgment}

We thank Jia Quan Li at Medical Research Center, People's Hospital of Guangxi Zhuang Autonomous Region, for excellent assistance in flow cytometry.

\section{Funding Sources}

This work was supported by grants from the National Natural Science Foundation of China (81360012) and Natural Science Foundation of Guangxi Zhuang Autonomous Region (2016GXNSFAA380269).

\section{Disclosure Statement}

No conflicts of interest, financial, or otherwise are declared by the author(s).

\section{Author Contributions}

M.-H.L. had full access to all of the data in the present study and takes full responsibility for the integrity of the data and data analysis; Nan Ma served as the principal investigator; X.-N.Z. and M.-H.L. contributed to the conception of the study; Z.-Y.H. and M.-H.L. contributed to the study design; M.-H.L., N.M., T.-T.D., Q.W., Z.-L.L., C.-F.Z. J.-F.Q., X.-J.T., and M.H. contributed to the laboratory investigations; N.M. and Z.-L.L. contributed to the data analysis and interpretation; M.-H.L. and N.M. contributed to the manuscript preparation; M.-H.L., J.B., X.-N.Z. and Z.Y. he contributed to the revision and editing of the manuscript.

\section{Data Availability Statement}

All data used to support the findings of this study are included within the article.

\section{References}

1 Barnes PJ. New therapies for chronic obstructive pulmonary disease. Med Princ Pract. 2010;19(5):330-8.

2 Barnes PJ. Therapeutic approaches to asthma-chronic obstructive pulmonary disease overlap syndromes. J Allergy Clin Immunol. 2015 Sep;136(3):531-45.

3 Mammen MJ, Sethi S. Macrolide therapy for the prevention of acute exacerbations in chronic obstructive pulmonary disease. Pol Arch Med Wewn. 2012;122(1-2):54-9.

4 Ni W, Shao X, Cai X, Wei C, Cui J, Wang R, et al. Prophylactic use of macrolide antibiotics for the prevention of chronic obstructive pulmonary disease exacerbation: a meta-analysis. PLoS One. 2015 Mar;10(3):e0121257.

5 Parameswaran GI, Sethi S. Long-term macrolide therapy in chronic obstructive pulmonary disease. CMAJ. 2014 Oct;186(15):114852.

6 Vermeersch K, Gabrovska M, Deslypere G, Demedts IK, Slabbynck H, Aumann J, et al. The Belgian trial with azithromycin for acute COPD exacerbations requiring hospitaliza- tion: an investigator-initiated study protocol for a multicenter, randomized, double-blind, placebo-controlled trial. Int J Chron Obstruct Pulmon Dis. 2016 Mar;11:687-96.

7 Raidt L, Idelevich EA, Dübbers A, Küster P, Drevinek P, Peters G, et al. Increased Prevalence and Resistance of Important Pathogens Recovered from Respiratory Specimens of Cystic Fibrosis Patients During a Decade. Pediatr Infect Dis J. 2015 Jul;34(7):700-5.

8 Zarogoulidis P, Papanas N, Kioumis I, Chatzaki E, Maltezos E, Zarogoulidis K. Macrolides: from in vitro anti-inflammatory and immunomodulatory properties to clinical practice in respiratory diseases. Eur J Clin Pharmacol. 2012 May;68(5):479-503.

9 Li M, Zhong X, He Z, Wen M, Li J, Peng X, et al. Effect of erythromycin on cigarette-induced histone deacetylase protein expression and nuclear factor- $\kappa \mathrm{B}$ activity in human macrophages in vitro. Int Immunopharmacol. $2012 \mathrm{Apr} ; 12(4): 643-50$.

10 Zhao Z, Tang X, Zhao X, Zhang M, Zhang W, Hou S, et al. Tylvalosin exhibits anti-inflam- matory property and attenuates acute lung injury in different models possibly through suppression of NF- $\kappa$ B activation. Biochem Pharmacol. 2014 Jul;90(1):73-87.

11 Vestbo J, Hurd SS, Agustí AG, Jones PW, Vogelmeier $\mathrm{C}$, Anzueto A, et al. Global strategy for the diagnosis, management, and prevention of chronic obstructive pulmonary disease: GOLD executive summary. Am J Respir Crit Care Med. 2013 Feb;187(4):347-65.

12 López-Campos JL, Tan W, Soriano JB. Global burden of COPD. Respirology. 2016 Jan; 21(1):14-23.

13 Sundar IK, Yao H, Rahman I. Oxidative stress and chromatin remodeling in chronic obstructive pulmonary disease and smoking-related diseases. Antioxid Redox Signal. 2013 May ;18(15):1956-71.

14 Yao H, Sundar IK, Ahmad T, Lerner C, Gerloff J, Friedman AE, et al. SIRT1 protects against cigarette smoke-induced lung oxidative stress via a FOXO3-dependent mechanism. Am J Physiol Lung Cell Mol Physiol. 2014 May;306(9):L816-28.
EM Regulates Cigarette Smoke-Induced Proinflammatory Mediator Release 
15 Fischer BM, Voynow JA, Ghio AJ. COPD: balancing oxidants and antioxidants. Int $\mathrm{J}$ Chron Obstruct Pulmon Dis. 2015 Feb;10: 261-76.

16 Kirkham PA, Barnes PJ. Oxidative stress in COPD. Chest. 2013 Jul;144(1):266-73.

17 Barnes PJ. Inflammatory mechanisms in patients with chronic obstructive pulmonary disease. J Allergy Clin Immunol. 2016 Jul; 138(1):16-27.

18 Schuliga M. NF-kappaB Signaling in Chronic Inflammatory Airway Disease. Biomolecules. 2015 Jun;5(3):1266-83.

19 Poulose N, Raju R. Sirtuin regulation in aging and injury. Biochim Biophys Acta. 2015 Nov; 1852(11):2442-55.

20 Vachharajani VT, Liu T, Wang X, Hoth JJ, Yoza BK, McCall CE. Sirtuins Link Inflammation and Metabolism. J Immunol Res. 2016;2016:8167273.

21 Gu C, Li Y, Xu WL, Yan JP, Xia YJ, Ma YY, et al. Sirtuin 1 Activator SRT1720 Protects Against Lung Injury via Reduction of Type II Alveolar Epithelial Cells Apoptosis in Emphysema. COPD. 2015 Aug;12(4):444-52.

22 Kim SY, Zhang Q, Brunmeir R, Han W, Xu F. SIRT1 Interacts with and Deacetylates ATP6V1B2 in Mature Adipocytes. PLoS One. 2015 Jul;10(7):e0133448.

23 Ghisays F, Brace CS, Yackly SM, Kwon HJ, Mills KF, Kashentseva E, et al. The N-Terminal Domain of SIRT1 Is a Positive Regulator of Endogenous SIRT1-Dependent Deacetylation and Transcriptional Outputs. Cell Rep. 2015 Mar;10(10):1665-73.

24 Rajendrasozhan S, Yang SR, Kinnula VL, Rahman I. SIRT1, an antiinflammatory and antiaging protein, is decreased in lungs of patients with chronic obstructive pulmonary disease. Am J Respir Crit Care Med. 2008 Apr 177(8):861-70

25 Yang SR, Wright J, Bauter M, Seweryniak K, Kode A, Rahman I. Sirtuin regulates cigarette smoke-induced proinflammatory mediator release via RelA/p65 NF-kappaB in macrophages in vitro and in rat lungs in vivo: implications for chronic inflammation and aging. Am J Physiol Lung Cell Mol Physiol. 2007 Feb;292(2):L567-76.

26 Guo L, Li S, Zhao Y, Qian P, Ji F, Qian L, et al. Silencing Angiopoietin-Like Protein 4 (ANGPTL4) Protects Against LipopolysaccharideInduced Acute Lung Injury Via Regulating SIRT1/NF-kB Pathway. J Cell Physiol. 2015 Oct;230(10):2390-402.

27 Mikura S, Wada H, Higaki M, Yasutake T, Ishii $\mathrm{H}$, Kamiya $\mathrm{S}$, et al. Erythromycin prevents the pulmonary inflammation induced by exposure to cigarette smoke. Transl Res. 2011 Jul;158(1):30-7.

28 Sundström C, Nilsson K. Establishment and characterization of a human histiocytic lymphoma cell line (U-937). Int J Cancer. 1976 May;17(5):565-77.

29 Sumiya $Y$, Ishikawa $M$, Inoue $T$, Inui $T$, Kuchiike D, Kubo K, et al. Macrophage Activation Mechanisms in Human Monocytic
Cell Line-derived Macrophages. Anticancer Res. 2015 Aug;35(8):4447-51.

30 Randall MJ, Haenen GR, Bouwman FG, van der Vliet A, Bast A. The tobacco smoke component acrolein induces glucocorticoid resistant gene expression via inhibition of histone deacetylase. Toxicol Lett. 2016 Jan;240(1):439.

31 Carp H, Janoff A. Possible mechanisms of emphysema in smokers. In vitro suppression of serum elastase-inhibitory capacity by fresh cigarette smoke and its prevention by antioxidants. Am Rev Respir Dis. 1978 Sep;118(3): 617-21.

32 Yang SR, Chida AS, Bauter MR, Shafiq N, Seweryniak K, Maggirwar SB, et al. Cigarette smoke induces proinflammatory cytokine release by activation of NF-kappaB and posttranslational modifications of histone deacetylase in macrophages. Am J Physiol Lung Cell Mol Physiol. 2006 Jul;291(1):L46-57.

33 Kojima J, Araya J, Hara H, Ito S, Takasaka N, Kobayashi K, et al. Apoptosis inhibitor of macrophage (AIM) expression in alveolar macrophages in COPD. Respir Res. 2013 Mar; 14(1):30.

34 Yu S, Gao B, Duan Z, Xu W, Xiong S. Identification of tripartite motif-containing 22 (TRIM22) as a novel NF- $\mathrm{kB}$ activator. Biochem Biophys Res Commun. 2011 Jul;410(2): 247-51.

35 Wang W. SIRT1 prevents atherosclerosis via liver-X-receptor and NF- $\mathrm{kB}$ signaling in a U937 cell model. Mol Med Rep. 2013 Jul;8(1): 23-8.

36 Kim SH, Kim KY, Yu SN, Seo YK, Chun SS, Yu HS, et al. Silibinin induces mitochondrial NOX4-mediated endoplasmic reticulum stress response and its subsequent apoptosis. BMC Cancer. 2016 Jul;16(1):452.

37 Yao H, Hwang JW, Sundar IK, Friedman AE, McBurney MW, Guarente L, et al. SIRT1 redresses the imbalance of tissue inhibitor of matrix metalloproteinase- 1 and matrix metalloproteinase- 9 in the development of mouse emphysema and human COPD. Am J Physiol Lung Cell Mol Physiol. 2013 Nov; 305(9):L615-24.

38 Wang J, Voellger B, Benzel J, Schlomann U, Nimsky C, Bartsch JW, et al. Metalloproteinases ADAM12 and MMP-14 are associated with cavernous sinus invasion in pituitary adenomas. Int J Cancer. 2016 Sep;139(6):132739.

39 Cong L, Chen W. Neuroprotective Effect of Ginsenoside Rd in Spinal Cord Injury Rats. Basic Clin Pharmacol Toxicol. 2016 Aug. 119(2):193-201.

40 Caito S, Rajendrasozhan S, Cook S, Chung S, Yao H, Friedman AE, et al. SIRT1 is a redoxsensitive deacetylase that is post-translationally modified by oxidants and carbonyl stress. FASEB J. 2010 Sep;24(9):3145-59.

41 Ji KL, Gan XQ, Xu YK, Li XF, Guo J, Dahab $M M$, et al. Protective effect of the essential oil of Zanthoxylum myriacanthum var. pubescens against dextran sulfate sodium-induced intestinal inflammation in mice. Phytomedicine. 2016 Aug;23(9):883-90.

42 Prins HJ, Daniels JM, Lindeman JH, Lutter R, Boersma WG. Effects of doxycycline on local and systemic inflammation in stable COPD patients, a randomized clinical trial. Respir Med. 2016 Jan;110:46-52.

43 Musal B, Turkyilmaz S, Beceriklisoy HB, Peker C, Ucar EH. Effects of Subclinical Mastitis on Serum Estradiol and Tumour Necrosis Factor Alpha Levels During Estrus in Dairy Cows. Kafkas Univ Vet Fak Derg. 2016;22(5): 653-8.

44 Kuete V, Mbaveng AT, Nono EC, Simo CC, Zeino M, Nkengfack AE, et al. Cytotoxicity of seven naturally occurring phenolic compounds towards multi-factorial drug-resistant cancer cells. Phytomedicine. 2016 Jul 15; 23(8):856-63.

45 Chen YM, Li X, Song GX, Liu M, Fan Y, Wu LJ, et al. Effect of LYRM1 knockdown on proliferation, apoptosis, differentiation and mitochondrial function in the P19 cell model of cardiac differentiation in vitro. J Bioenerg Biomembr. 2016 Feb;48(1):33-41.

46 Ramos FL, Criner GJ. Use of long-term macrolide therapy in chronic obstructive pulmonary disease. Curr Opin Pulm Med. 2014 Mar; 20(2):153-8.

47 Miravitlles M. Prevention of exacerbations of COPD with pharmacotherapy. Eur Respir Rev. 2010 Jun;19(116):119-26.

48 Friedlander AL, Albert RK. Chronic macrolide therapy in inflammatory airways diseases. Chest. 2010 Nov;138(5):1202-12.

49 Donmez G, Guarente L. Aging and disease: connections to sirtuins. Aging Cell. 2010 Apr; 9(2):285-90.

50 Haigis MC, Sinclair DA. Mammalian Sirtuins: Biological Insights and Disease Relevance. Annual Review of Pathology-Mechanisms of Disease. 5. Palo Alto: Annual Reviews; 2010. pp. 253-95.

51 Wiegman $\mathrm{CH}$, Michaeloudes C, Haji G, Narang P, Clarke CJ, Russell KE, et al.; COPDMAP. Oxidative stress-induced mitochondrial dysfunction drives inflammation and airway smooth muscle remodeling in patients with chronic obstructive pulmonary disease. $\mathrm{J} \mathrm{Al}$ lergy Clin Immunol. 2015 Sep;136(3):769-80.

52 Andrés MT, Viejo-Díaz M, Fierro JF. Human lactoferrin induces apoptosis-like cell death in Candida albicans: critical role of $\mathrm{K}+$-channel-mediated $\mathrm{K}+$ efflux. Antimicrob Agents Chemother. 2008 Nov;52(11):4081-8.

53 Bell EL, Guarente L. The SirT3 divining rod points to oxidative stress. Mol Cell. 2011 Jun; 42(5):561-8.

54 Larsson K. Inflammatory markers in COPD. Clin Respir J. 2008 Oct;2(Suppl 1):84-7.

55 Zhou XL, Xu JJ, Ni YH, Chen XC, Zhang HX, Zhang XM, et al. SIRT1 activator (SRT1720) improves the follicle reserve and prolongs the ovarian lifespan of diet-induced obesity in female mice via activating SIRT1 and suppressing mTOR signaling. J Ovarian Res. 2014 Oct; 7(1):97. 
56 Wang W, Lin Q, Lin R, Zhang J, Ren F, Zhang $\mathrm{J}$, et al. PPAR $\alpha$ agonist fenofibrate attenuates TNF- $\alpha$-induced CD40 expression in 3T3-L1 adipocytes via the SIRT1-dependent signaling pathway. Exp Cell Res. 2013 Jun;319(10): 1523-33.

57 Jin SE, Kim OS, Yoo SR, Seo CS, Kim Y, Shin $\mathrm{HK}$, et al. Anti-inflammatory effect and action mechanisms of traditional herbal formula Gamisoyo-san in RAW 264.7 macrophages. BMC Complement Altern Med. 2016 Jul; 16(1):219.

58 Chun P. Role of sirtuins in chronic obstructive pulmonary disease. Arch Pharm Res. 2015 Jan;38(1):1Arch Pharm Res. 2015 Jan; 38(1):1-1010.
59 Yeung F, Hoberg JE, Ramsey CS, Keller MD, Jones DR, Frye RA, et al. Modulation of NFkappaB-dependent transcription and cell survival by the SIRT1 deacetylase. EMBO J. 2004 Jun;23(12):2369-80.

60 Conti V, Corbi G, Manzo V, Pelaia G, Filippelli A, Vatrella A. Sirtuin 1 and aging theory for chronic obstructive pulmonary disease. Anal Cell Pathol (Amst). 2015;2015: 897327.

61 Polesskaya A, Naguibneva I, Duquet A, Bengal E, Robin P, Harel-Bellan A. Interaction between acetylated MyoD and the bromodomain of CBP and/or p300. Mol Cell Biol. 2001 Aug;21(16):5312-20.
62 Chen LF, Greene WC. Regulation of distinct biological activities of the NF-kappaB transcription factor complex by acetylation. J Mol Med (Berl). 2003 Sep;81(9):549-57.

63 Liu Z, Jiang C, Zhang J, Liu B, Du Q. Resveratrol inhibits inflammation and ameliorates insulin resistant endothelial dysfunction via regulation of AMP-activated protein kinase and sirtuin 1 activities. J Diabetes. 2016 May; 8(3):324-35.

64 Qu L, Yu Y, Qiu L, Yang D, Yan L, Guo J, et al. Sirtuin 1 regulates matrix metalloproteinase-13 expression induced by Porphyromonas endodontalis lipopolysaccharide via targeting nuclear factor- $\mathrm{KB}$ in osteoblasts. J Oral Microbiol. 2017 Apr;9(1):1317578. 